\title{
ACTIVATING TUIA LEARNING ENVIRONMENT. WEAVING WAYS OF KNOWING. EXPLORING LIFE'S INTERCONNECTIONS. NOURISHING SHARED FUTURES
}

\author{
Julie Crocker, Emma Morris and Alexa Forbes
}

\author{
Mā te rongo, ka mōhio; \\ Mā te mōhio, ka mārama; \\ Mā te mārama, ka mātau; \\ Mā te mātau, ka ora \\ From listening comes awareness; \\ from awareness comes understanding; \\ from understanding comes knowledge; \\ from knowledge comes life and well-being
}

This article is co-authored by Emma Morris and Julie Crocker. We are part of a group of six who are activating the Tuia Learning Environment (formerly known as The Centre for Socio-Ecological Learning) in its early conceptual stages, along with Dave Hursthouse, Cameron Ryan, Chris Anderson and Sam O'Sullivan. We are both current students with Capable NZ, where Emma is exploring a master's in professional practice and Julie exploring a graduate diploma in professional practice (leadership for change). Both inquiries are focused on exploring transformative learning experiences, through different lenses. Emma's master's project is a discovery into the life-force of learning, how to vivify learning experiences and nourish the vitality of learners. Julie is exploring the power of movement and body intelligence to inspire personal and collective transformation. In this article we tap into our personal essences to describe our shared vision for this learning environment.

In this article we're setting out to take you with us through the creation story of this organisation, where we've come from, where we are now and where we are heading. Our challenge here is to introduce the Tuia Learning Environment (Tuia) in a way that balances clear, accessible language with ecological, metaphoric language. This article will discuss the why, what, how and who of Tuia through the metaphor of a whole natural landscape, "ki uta ki tai" (from the mountains to the sea). In this way the article becomes part explanation, part learning experience. This approach models one of Tuia's core organisational 'theories of change'; the belief that by being aware that all life is interconnected we deepen our ability to nourish a thriving people and planet. We believe this can be facilitated through transformative learning experiences that deeply question our way of thinking and knowing. Our hope is that we stimulate this experience at all stages of contact with the Tuia Learning Environment, including the experience of reading this article.

There is a growing understanding of how our outside environment interacts with our internal states, including how the patterns of language can affect a speaker's worldview, or cognition. We have been experiencing this ourselves, as the two of us have embarked on Te Ara Reo Māori (the path to the Māori language) with Te Wānanga o Aotearoa. To us, this journey has felt like a dance between the language and the culture, the two so wholly enmeshed that we cannot tell where one starts and the other ends. The deeper we are welcomed into Te Ao Māori (the Māori world), the clearer we can understand how everything is connected. We are grateful for the wisdom of tangata whenua (people of the land) as it is in light of this wisdom that we can foresee a beautiful future together. 
With that in mind, welcome to this experience. We invite you to this story of Tuia which starts to speak the change that we wish to live. Take a moment to breathe deeply, grounding into your body. ta kina (breathe in), ha puta (breathe out). Presence yourself in your space, at this time, and read on.

We see Tuia as "Ki uta ki tai", a whole landscape system, from the mountains to the sea

Those who interact with Tuia experience a dynamic cycle through the learning environment;

a transformative learning experience.

Te Moana (the ocean) is the big picture,

the wider systems changing in response to the learning environment.

We seek to cultivate rich upstream conditions in the learning environment that have flow on effects to the ocean, the desired sea of change. As the learning environment grows the landscape changes, causing ripple effects to flow in all directions. We seek to shift the ocean from one dominated by broken systems to one abundant with deep relationships.

The dream for Tuia emerged from the desire to unite in the face of our rapidly changing, highly complex times. Tuia is a response to the current stuck and broken systems which are resulting in ecological decline and social injustice. We believe that shifting these systems will start with collectively questioning the dominant ways of knowing which neglect the role humans play within wider systems. When we ignore the relationships between ourselves and the systems we are nested within, we are unable to perceive our personal impact on the planet. We privilege ways of behaving and knowing that can marginalise and disempower others.

Every person feels reality in a different way, and sees it through a lens informed by their unique cultural stories and values. Our deepest wisdom may only emerge when we weave different ways of knowing into the cultures they emerge from. If we question the prevailing ways of knowing we can begin to observe the relationships - in-between all elements of life. We start to see what indigenous wisdom and

\section{KI UTA KI TAIFROM MOUNTAINS TO SEA}

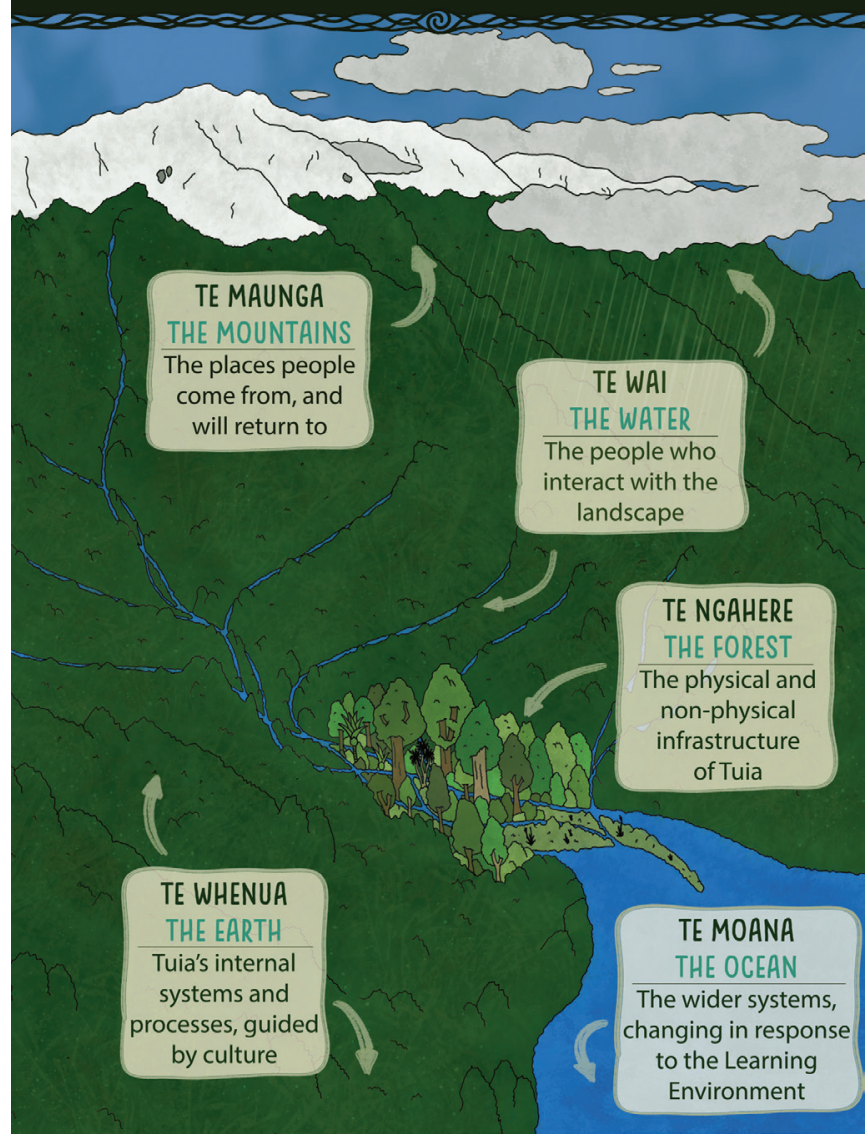

Figure I. Ecological metaphor for Tuia Learning Environment. 
holistic sciences have been indicating for eons: that everything is interconnected. We see how personal decisions and patterns of behaviour affect social inequity or ecological decline - how our inner worlds affect our outer worlds. By exploring the interconnection between inner and outer systems we can become aware of the changes we can make to nourish a shared future where the well-being of both people and planet thrive.

Tuia will create space for collective sharing, and thus a space for collective learning. Mehemea ka moemoeā ahau, ko ahau anake mehemea ka moemoeā tātou, ka taea e tātou - If I dream alone, only I benefit, if we all dream together, we can succeed together. This whakatauki (Māori proverb) from Te Peua Herangi (Waikato Tainui) reminds us of the significance of dreaming. Tuia is a dreaming space - a space for visioning, knowledge and learning, a space for expanding what is possible, a space for connections. When we dream alone the benefits will be limited. When we dream together, we open the possibility for the emergence of a genuine shared future which supports collective wellbeing.

Te Ngahere (the forest) is the physical infrastructure;

the buildings, the natural spaces, and the non-physical infrastructure; the learning experiences, the businesses and the organisation as a whole.

Each tree in the forest nurtures a distinct area of focus through communication and resources.

Each tree has a number of branches, these are the working groups that turn energy into action.

Tuia will be a land-based learning environment focused on contemporary skills in regenerative practices for human and planetary wellbeing. The learning environment will offer a wide range of short-term and long-term learning experiences to equip people and communities to adapt to fast-changing environmental and social climates. The learning experiences will be oriented towards land-based learning, social and cultural learning and wellbeing, woven together to provide integrated learning experiences. Examples of learning experiences include: regenerative agriculture, permaculture design, waste management, decolonisation, Te Tiriti o Waitangi, living organisations, physical health practices, mindfulness, emotional awareness, behavioural and movement therapy.

At the beating heart of the Tuia Learning Environment will be a welcoming, living learning centre. This will include indoor and outdoor classrooms, spaces for events, places for wellbeing as well as short-term accommodation. To embed learning in place, build capacity and financially support the learning centre, the wider landscape will integrate income-generating activities and demonstration systems. For example, a learning experience focused on organic horticulture could offer experiences of a successful orchard operation on the land. This orchard operation could be financially supporting the course and provide employment opportunities to learners beyond the course. In this way the wider learning environment becomes the classroom.

For humans and the environment to flourish, we need a shift in learning. In shifting how we learn, we shift how we see the world, how we live in it and how we choose to thrive. We want to shift away from seeing education as something that can be compartmentalised, planned and measured. Instead, we seek guidance from the natural world and Te Ao Māori where we are learning that learning experiences are alive; they are dynamic, living systems. When we treat our learning experiences as living systems, we awaken a sense of aliveness, vibrancy and self-creating creativity. By designing learning experiences to resonate with the structures and rhythms of nature they hold space for uncertainty and paradox; adaptive systems that are continually changing. This approach creates space for ways of knowing and learning that are co-created. In providing space for different ways to interact and connect, what emerges is something new and contextually appropriate, something no single learner could have foreseen or created on their own.

Learners are treated as living systems too, the whole person must be cared for; te taha hinengaro (mental wellbeing), te taha tinana (physical well-being), te taha wairua (spiritual well-being) and te taha whanau (the well-being of the family). Rather than traditional transmission teaching, learning will be explored through a balanced experience of different learning styles that feed total wellbeing. This means integrating the more inner/felt dimensions (through creative expression; arts, story, play, movement) as well as weaving theoretical and practical dimensions. 


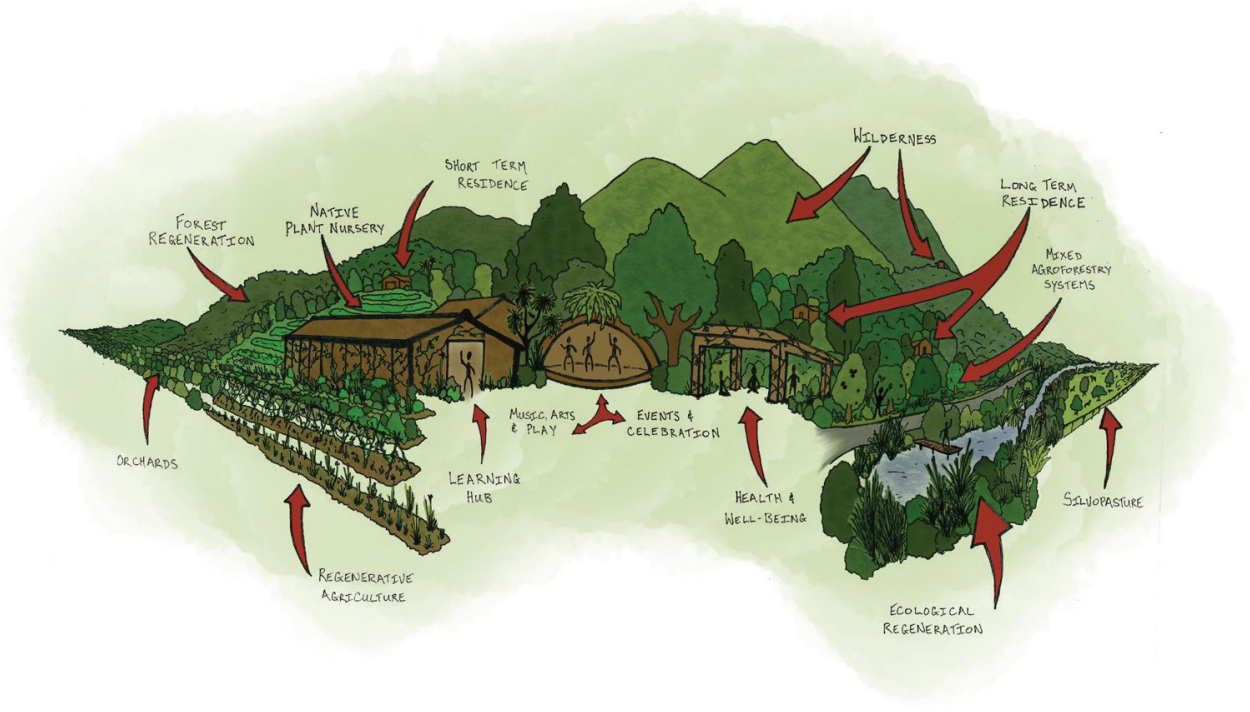

Figure 2. Sketch of Tuia Learning Centre.

The learning experiences will be facilitated by a diversity of local, national and international facilitators, who will weave different ways of knowing, across cultures, generations and backgrounds. Tuia intends to collaborate and partner with a range of organisations and industries. For example, tertiary learning providers could have in-person learning retreats offered at Tuia learning environment to cater for their growing online classes in areas such as leadership for change. Partnerships with education providers at all levels will offer youth opportunities to engage in change-making work before they leave school/university. Partnerships with commercial organisations could be fostered, to provide workplace and organisational training and career development. Governmental organisations such as local councils could engage with us to learn fresh approaches to guide their policy development (such as how to deliver on climate emergency declarations and wellbeing targets).

Mā te huruhuru ka rere te manu

Adorn this bird with feathers to enable it to fly

This whakatauki inspires us to focus on developing the capacity of learners to express their unique potential to evolve themselves and contribute to the wider systems they are part of. Learners will be encouraged to take responsibility for their own learning, cultivating space for cross-cultural sharing. By experimenting with dynamic experiences which explore relationships and systems, we can reflect on the changes we can make to support a future where both people and planet thrive.

Te Whenua (the earth) is the culture of the learning environment, the internal systems and active processes that provide the foundation for the healthy growth of the ecosystem.

We appreciate that for anything to grow well, the soil must be rich and healthy. We see this soil as our organisational culture and systems, which everything grows from. That is why we have devoted considerable time and effort into articulating our culture and designing living systems with constant feedback.

Our organisational systems and processes are guided by the wisdom of the natural world; observing its patterns, systems and relationships. Weaving our inner and outer worlds we also look to ourselves, because we are nature 
too; wise and alive, also with patterns, systems and relationships. This way of understanding ourselves and our co-created culture feels like remembering a simple truth; that we are nature living, learning and knowing itself! As we practice Te Reo Maori we are being invited into this remembering, where we are learning how this way of knowing is so deeply embedded into Te Ao Māori. We are learning to speak, learn and behave in a way that holds an understanding of pluralities, complexities and interconnections. This affects the way we perceive the world, relate to each other and how we approach our systems and processes - as alive, nested and interconnected.

An example of one of our organisational processes is our Holistic Decision Making (HDM) model, which is a cultural framework for making decisions. Among other internal systems, the HDM is one of the most significant elements of the soil of the learning environment - it is the living culture of this organisation. It informs both the approach we take to achieve our vision and the way we adapt and evolve. It offers support for making decisions that align with the vision and purpose of the project. The HDM framework acts as a filter and not only allows decision making processes to unfold organically, but also for people and decisions to be held accountable to it. Embedded in the framework is an understanding of the whole in balance with the parts, and the awareness of the relationships in between.

The HDM holds a series of truth statements - what needs to be true to realise our vision. Each truth statement contains multiple enabling actions - the more tangible actions required for the truth statements to be true, and the vision to be realised. The following image illustrates one of these truth statements surrounded by its enabling actions:

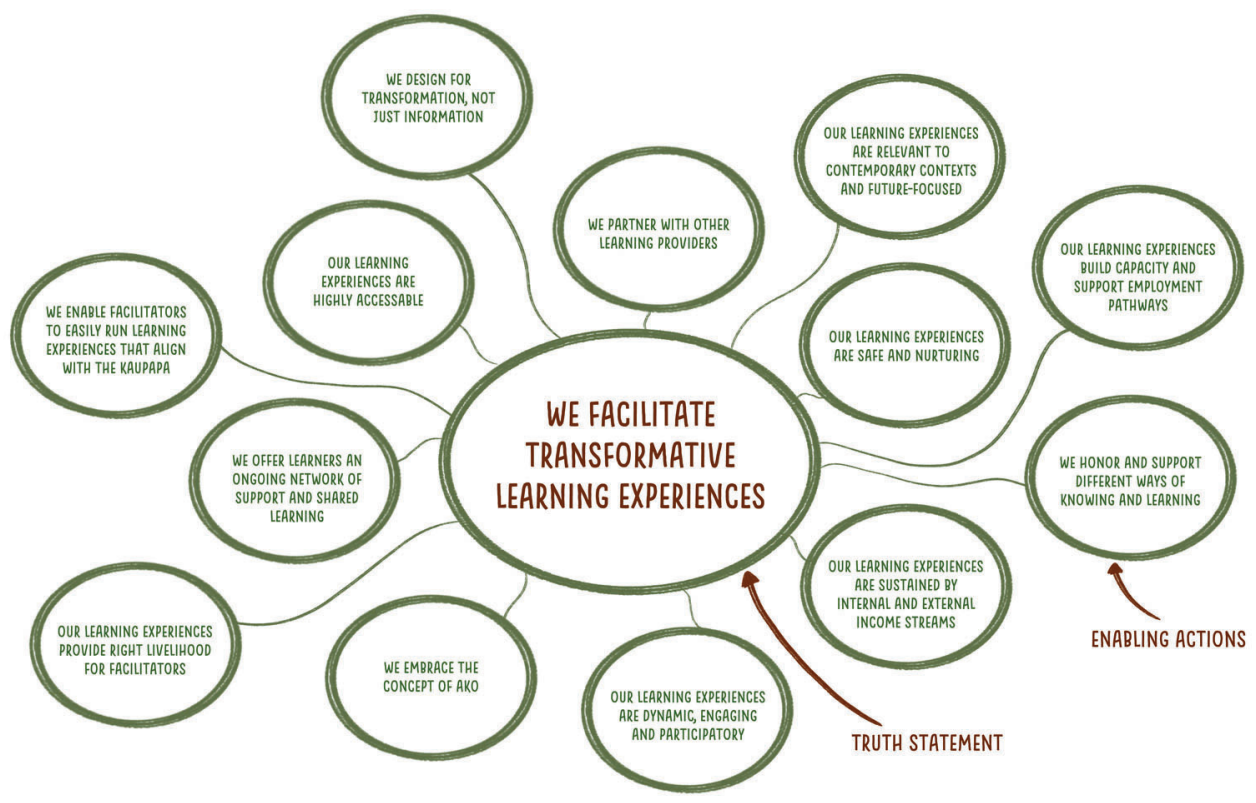

Figure 3. One of the truth statements of our HDM surrounded by enabling actions.

Other layers of soil that make up the how are our internal governing systems which are based on transparency, dispersing power, autonomy and self-organisation. For decision-making, we use consent-based decision making and advice processes to dismantle power-over hierarchies and empower groups and individuals. Our organisational structure is a variation of sociocratic governance, conceptualised as a forest. The forest is made up of mostly autonomous sub-organisations (the trees). These sub-organisations are made up of more specific task-oriented groups (the branches). Humans act like fungi, moving information and nutrients between all the trees in the forest, ensuring that the trees are interconnected and mutually supportive. 

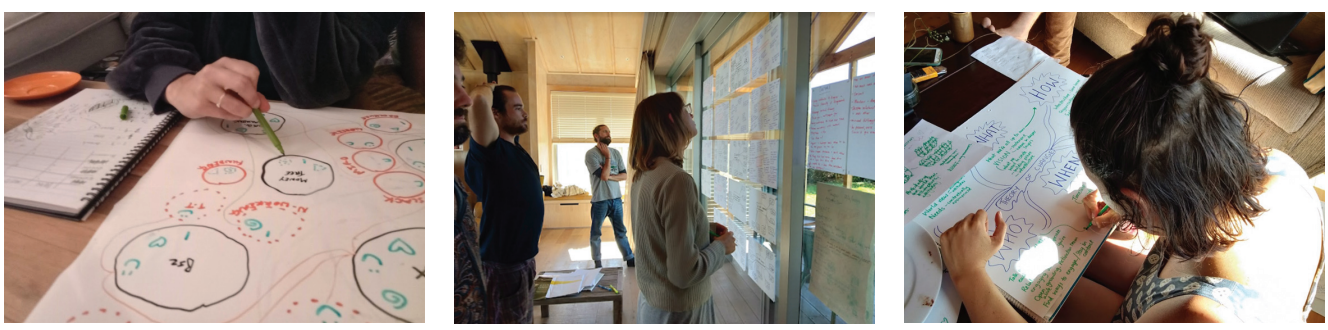

Figure 4. Images from Activation group gatherings.

To support this organisational model we use a range of integrated digital tools that help with efficiency, transparency and visualisation. For online communication we use an application called Slack where discussions are themed by sub-group (tree) of task-group (branch). This means while we aren't all involved in the same groups, we can follow what is happening in all areas while being able to focus communications into the relevant place. We use online the visual mapping technology Miro to visualise everything (such as our HDM in the image above). This means we can pull work out of word documents onto large digital whiteboards for effective imaging. We also use the Google Drive suite for shared online information databases, email and calendar, the task management application Asana and online video software Zoom for high quality video calling given we live in different areas of the country.

For the last two years, an 'activation group' has existed to bring this learning environment to life. For now, this group is stewarding the establishment of Tuia nurturing this initiative in its early stages and cultivating a space that is ready (enough) for the engagement of many, many more people. The activation group has had weekly gatherings, monthly weekend workshops and mini-working groups in between. These have been intensive sessions of mahi aroha (work for love) where we make decisions and strategise collectively. We have been nurturing the soil, clarifying intention, establishing essential systems, and laying the legal foundations.

As we are transitioning to the new organisational structure discussed above, these processes will change. Instead of activation groups meeting together we wish to start experimenting with meeting with the sub-groups (trees) and task groups (branches) instead. We are getting ready to let go of the existing centralised decision-making power to provide room for more autonomy and empowerment. The activation group will cease to exist, providing space for the organisational 'forest' to grow.

As we wade through uncharted waters during this transition, processes like our cultural framework become incredibly significant. By ensuring that our culture and systems are healthy, we can be confident that the new growth will thrive.

'Te toto o te tangata, he kai; te oranga o te tangata, he whenua'

While food provides the blood in our veins, our health is drawn from the land.

Te Wai (the water) is the people who interact with the learning environment; experiencing a dynamic cycle. They arrive from the mountains of their own experiences and flow through the landscape, guided by their own process of learning. As they flow, they mix with other waters, converging in a shared future; more resilient and united at the ocean. Like water they transpire, returning to their own communities, showering their gifts and offering new perspectives and skills for growth, continuing the cycle.

While the activation group has been stewarding the establishment of Tuia, it is already shaped by the rivers of many others. Through our passions, mahi (work), education, whānau and friendships we have a growing network, crossing diverse communities. Our communities include: local iwi and mārae; the New Zealand permaculture community; conscious movement communities; activism groups; mindfulness communities; ecological groups; festival communities; alternative farming communities; local board and councils; wānanga, universities, polytechnics and local schools. 
People from these communities, and others, are deeply influencing the development of Tuia and are continuing to be engaged through our online communications platforms such as our regular newsletter 'mycelium mail'. Within this network is a group of people who have expressed interest in being involved in Tuia more directly and we are currently in the process of developing pathways for their participation as we transition into the new organisational model.

A significant stream that has been mixing with these waters has been that of the leadership for change whânau. By participating in a learning community that embraces reflection and different ways of knowing we have experienced the capacity for collective learning. In this community of learners, we are encouraged to suspend assumptions and enter into genuine dialogues together, allowing the collective to access insights we wouldn't be able to access by ourselves. We are experiencing a learning environment within the leadership for change whānau which influences the wider Tuia learning environment that we are cultivating.

Ki te kore te iwi, e kore koe i kiia - he tangata.

Without the people, you are diminished, you are nobody

We see humans as an integral part of the wider system. For us, it is crucial that Tuia remains socially engaged, integrated and outward facing. As Tuia grows we wish to continue to nurture these relationships, increasing engagement and interactions from these and other communities (see image below) to form symbiotic relationships that enable community resilience.

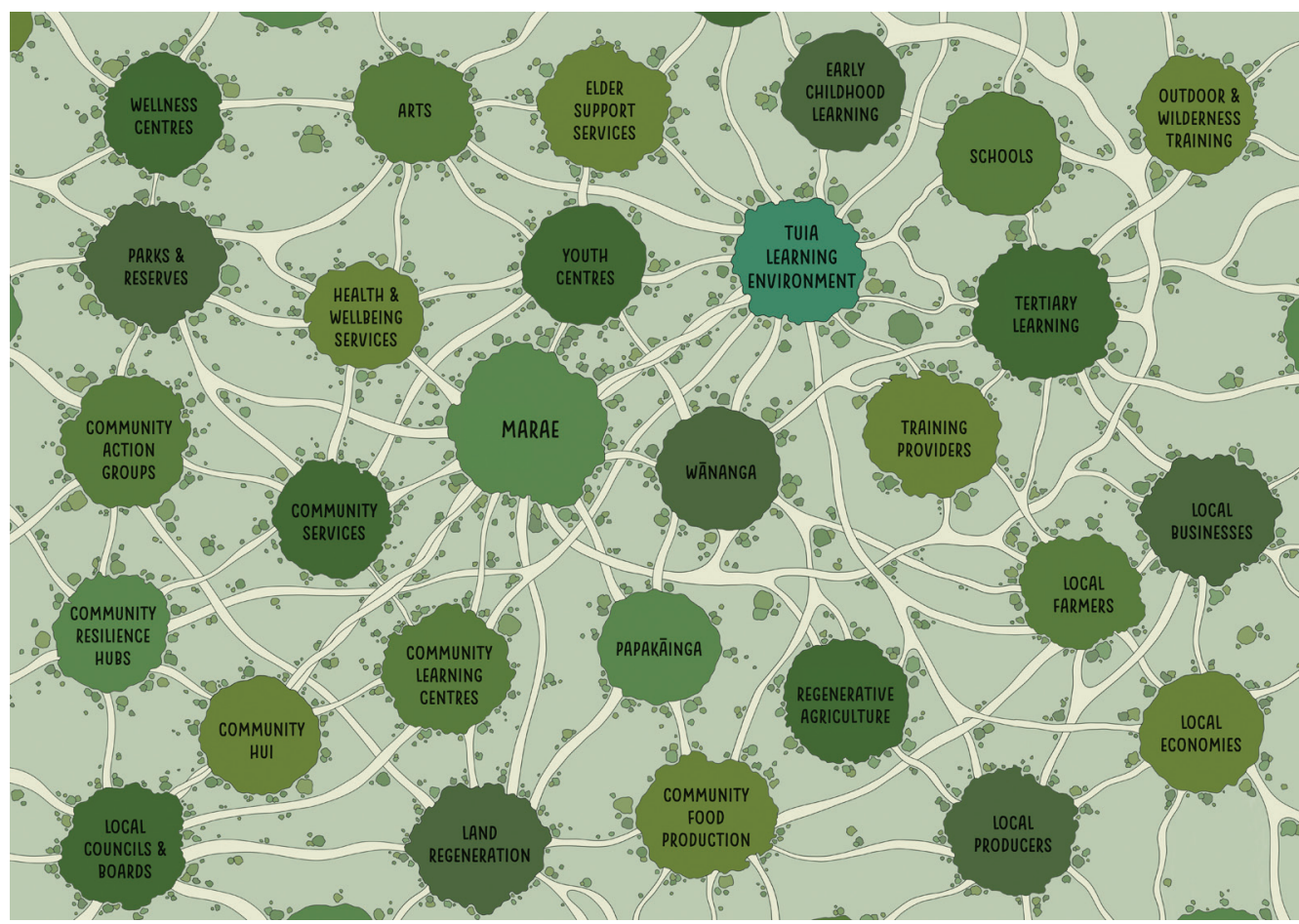

Figure 5. Community connections. 
As we are writing this journal article we are preparing for a significant transition stage for Tuia. Within the next few months we wish to evolve Tuia from a six-person project team to an expanding not-for-profit organisation. This means registering Tuia as a charitable trust, solidifying our organisational structure and business model, and launching the website. To enable to dissolution of our activation team and bring others on board, we are working on developing clear pathways for engagement, including processes for on-boarding and off-boarding. We are formalising a group of advisors to support Tuia and continuing to nourish partnership opportunities. Once registered as a trust we will be able to receive funding, with the immediate funding focused on acquiring land. We will be evolving from a conceptual learning environment to a rooted and expanding learning environment.

Tungia te ururoa kia tupu whakaritorito te tupu o te harakeke

Set the overgrown bush alight, and the new shoots will spring up.

We hope that this story has introduced you to the Tuia Learning Environment in a way that models the creative change we wish to live. We play with metaphors because we are actively trying to re-frame the way that we see the world. The more we explore how Tuia acts like a living system the more we start to understand it as a living system; whole, vibrant and alive. To us, Tuia is not a metaphor for a living system, it is a living system. It is a whole system, part of a wider system. It is part of a deeply interconnected network of people communities and environments. By listening to the wisdom we are receiving from Te Ao Māori and the natural world, and weaving this with our unique perspectives, we are deepening our understanding of these relationships. By holding space for uncertainty, paradox and change we provide space for the emergence of something new and exciting, something we couldn't have foreseen on our own.

Like the waters who interact with the Tuia Learning Environment, you have entered this story from your mountain; your home communities and contexts. You are reading this from your base cultural foundation and what you have learned from this experience is guided by your unique way of seeing, learning and being. By engaging further with Tuia you will help to shape the environment and it will in turn shape you. We invite you to participate in this dreaming space, this learning space. We invite you to join us in dreaming together to support a flourishing, shared future.

Ko ahau te taiao, ko te taiao, ko ahau

The ecosystem defines my quality of life 
Emma Morris is a creative coordinator and dynamic educator who explores the edge between making systemic change and engaging at the flax roots level. Co-owner of the consultancy business Nature Working, she is currently the project coordinator of the Waiheke Collective. Emma is passionate about social and ecological regeneration through the lens of re-imagining ways of learning. She is activating a not-for-profit organisation, Tuia Learning Environment, and undertaking a Masters with Otago Polytechnic developing a Learning Model to vivify learning experiences and nourish the vitality of learners.

Julie Crocker is a conscious dance facilitator and an all-round regenerative change enthusiast. She treasures a world view of profound interconnection between all things, which feeds her WHY and purpose in life. Julie's background has been working and volunteering in grass-roots charitable and community led organisations involved with food rescue and place-making. Julie is currently studying a Graduate Diploma in Leadership for Change with Otago Polytechnic focused on facilitating transformation through movement and dance. She's also part of a team activating Tuia Learning Environment, a regenerative education environment weaving the wellbeing of inner and outer ecologies.

Alexa Forbes is a facilitator on the graduate programmes in sustainable practice at Otago Polytechnic, Alexa supports working with others to find innovative and collaborative solutions to issues. At Scope Media she provides mentorship and strategic governance advice. Prior to these roles, Alexa worked for many years as a communicator - as a journalist and later as director of a PR company.

Contact the authors at: ecosystem.learning@gmail.com

The content of this article is in the early development stages, including the name Tuia Learning Environment, and is all subject to change. 